\title{
ORIGINAL ARTICLE \\ Medication before and after a spinal cord lesion
}

\author{
EK Jensen ${ }^{1,2}$ and F Biering-Sørensen ${ }^{1,2}$
}

\begin{abstract}
Objective: To map the impact of spinal cord lesion (SCL) on medication. Study design: Registration of medication for 72 patients before SCL and at discharge from the Department for Spinal Cord Injuries.
\end{abstract}

Setting: Department for Spinal Cord Injuries, East Denmark.

Methods: The changes in medication for each Anatomical Therapeutic Chemical (ATC) Classification System group were registered for all patients, who were discharged from Department for Spinal Cord Injuries during 2010. The changes in medication per se were calculated for different parts of the population: non-traumatic, traumatic patients, men, women, paraplegia, tetraplegia, American Spinal Injury Association Impairment Scale (AIS) A, B or C, AIS D, age 0-45, 46-60 and 60+. In addition, comparisons of changes in medication were made between complementary parts of the population.

Results: The overall increase in medication after SCL was 3.29 times $(P<0.001)$. Statistically significant increases were seen for most medicine categories. When studying subgroups of the population, the increase was most constantly seen for the medicine in the groups 'Alimentary tract and metabolism' and 'Nervous system'. The highest overall increases were seen in patients with AIS A, B and C compared with AIS D $(P<0.05)$. There was no difference between traumatic and non-traumatic SCL, men and women, and younger compared with older patients.

Conclusion: SCL elicits a general massive need for medicine. The relative increase is most pronounced for the more severely injured (AIS A, B and C). The increase in medication may have implications for side effects and for the economy of all involved.

Spinal Cord (2014) 52, 358-363; doi:10.1038/sc.2014.20; published online 11 March 2014

Keywords: spinal cord injury; paraplegia; tetraplegia; medication; traumatic; gender

\section{INTRODUCTION}

A spinal cord lesion (SCL) has a broad impact on body functions. For many the first association with an SCL may be a person in a wheelchair. But the everyday life for people with SCL may involve impairment of most body functions below the neurological level of the SCL. There have over the years been a change in the causes of death after SCL from being primarily due to urinary tract diseases ${ }^{1}$ to increasing numbers of deaths due to cardiovascular diseases (mainly ischemic heart disease $)^{1-3}$ and respiratory complications, ${ }^{1-4}$ thus becoming similar to the causes of death in the general population.

Still people with SCL are at high risk of developing disturbances related to the urinary tract,,${ }^{5,6}$ and bowel, ${ }^{7-9}$ together with several other physical and psychological challenges.

Prospectively collected data in the acute care of SCL have also shown that the most common secondary complications were urinary tract infections (35.6\%), pneumonia $(33.0 \%)$, neuropathic pain $(19.5 \%)$, delirium $(18.6 \%)$ and pressure ulcers $(18.6 \%) .{ }^{10}$ In addition, the frequency of medical complication increases with advancing age. For example, among persons above 60 years at the time of SCL, $47 \%$ had at least one pressure ulcer during initial hospitalization, $30 \%$ developed pneumonia, $11.4 \%$ had deep vein thrombosis, $10 \%$ had a gastrointestinal hemorrhage and $5.7 \%$ had a renal stone. ${ }^{4}$ The risk of developing a kidney stone is $50 \%$ higher for people with SCL who are at least 55 years of age compared with those aged 25-34 years. Similarly the risk of developing a pressure ulcer is $30 \%$ higher in people with SCL who were at least 50 years of age compared with individuals aged 15-29 years, even after controlling for other risk factors.

Because the age at SCL has increased over the last two decades, ${ }^{4}$ the frequency of medical complications has likewise increased.

Hitzig et al. ${ }^{11}$ studied secondary health complications in SCL individuals with traumatic as well as non-traumatic SCL. They found the prevalence of cardiac complications, high blood pressure and respiratory complications increased with age, while autonomic dysreflexia, bladder infections, psychological distress and drug addiction decreased with age. Those who had complete SCL were more associated with bladder infections, pressure ulcers and autonomic dysreflexia, while individuals with paraplegia had a higher prevalence of high blood pressure and bowel problems. Several of these challenges will imply that the individuals with SCL will need various kinds of medication to assist in overcoming their impairments. The aim of this study was to contribute to an evaluation of the pattern of changes in medication after SCLs thus hoping to facilitate further studies in the field. To accomplish this, we have used the Anatomical Therapeutical Chemical (ATC) Classification System (http://www.whocc.no/atc_ddd_methodology/history/).

${ }^{1}$ Department for Spinal Cord Injuries, Glostrup University Hospital, University of Copenhagen, Copenhagen, Denmark and ${ }^{2}$ Faculty of Health and Medical Sciences, University of Copenhagen, Copenhagen, Denmark

Correspondence: Dr EK Jensen, Department for Spinal Cord Injuries, Glostrup University Hospital, Havnevej 25, 3100 Hornbaek, Denmark

E-mail: elmo.jensen@dadlnet.dk

Received 21 August 2013; revised 5 January 2014; accepted 28 January 2014; published online 11 March 2014 


\section{MATERIALS AND METHODS}

For classification of the medicine consumption before and after SCL, the ATC Classification System was used. The ATC Classification System is controlled by the WHO Collaborating Centre for Drug Statistics Methodology, and was first published in 1976 (http://www.whocc.no/atc_ddd_methodology/history/). The classification system divides medicines into different groups according to the organ or the system on which they act and/or their therapeutic and chemical characteristics. In the ATC system, medicines are classified into groups at five different levels (http://www.whocc.no/atc/structure_and_principles/). The first level of the code indicates the anatomical main group and consists of one letter. There are fourteen main groups (Table 1). This level only is used in the present study, as more detailed systematic description will be questionable due to the limited number of patients included in the study. For clarification, we will in certain instances provide a more detailed description of the medicines used in specific ATC groups.

For each patient, the information on pre-lesion and post-lesion medication was retrieved from hospital case records and matching documentation in the electronic patient medication recordings. Both regular and on-demand medications were always recorded. Unprescribed medications were likewise included according to their ATC codes, that is, for example laxatives and vitamins as $\mathrm{A}$, and iron as $\mathrm{B}$.

The neurological level and the severity according to the American Spinal Injury Association Impairment Scale (AIS) of the SCL were recorded. ${ }^{12}$

\section{Population}

The study group consisted potentially of 72 consecutive patients with SCL, who during 2010 were discharged from the Department for Spinal Cord Injuries, which cover East Denmark with a population of $\sim 2.5$ mill. inhabitants. Four of these patients were not included in the calculations due to lack of information on medication before the SCL, because the SCL had happened abroad (two women aged 48 and 63, two men aged 65 and 82 with the SCL levels T12, C1, T5 and C3 respectively). For all four, the SCL was nontraumatic.

For the remaining 68 patients (94\%) included in the study, the number of days from the SCL till the discharge from the clinic was in mean $191 \pm 42$ (s.d.) days, median 179 , range $43-483$.

Age, gender, level (tetraplegia/paraplegia) and severity of lesion according to the AIS, and by cause of SCL (traumatic and non-traumatic) are given for the included patients in Table 2. Only 5 of $26(19.2 \%)$ women had a traumatic SCL, whereas it for men was 23 of $42(54.8 \%)$. This gender difference is statistically significant $(P<0.01)$.

Of the 33 persons belonging to AIS A, B or C 25 (76\%) were men, the SCL was traumatic for 17 (52\%).The trauma was caused by traffic accidents in nine individuals, sports accidents in three, falls from the same level in one and falls

Table 1 The fourteen main groups in the ATC (Anatomical Therapeutic Chemical) Classification System

\begin{tabular}{ll}
\hline Code & Contents \\
\hline A & Alimentary tract and metabolism \\
B & Blood and blood forming organs \\
C & Cardiovascular system \\
D & Dermatologicals \\
G & Genito-urinary system and sex hormones \\
H & Systemic hormonal preparations, excluding sex hormones and insulins \\
J & Antiinfectives for systemic use \\
L & Antineoplastic and immunomodulating agents \\
M & Musculo-skeletal system \\
$\mathrm{N}$ & Nervous system \\
P & Antiparasitic products, insecticides and repellents \\
R & Respiratory system \\
S & Sensory organs \\
V & Various \\
\hline
\end{tabular}

from a higher level in four individuals. The corresponding pattern for the 35 individuals in AIS group D was 17 (49\%) men, the SCL was traumatic for $11(31 \%)$, that is, due to traffic accidents in two individuals, falls from the same level in five, falls from a higher level in three and violence was the cause in one individual.

\section{RESULTS}

In Table 3, the overall population is seen to increase their total medicine consumption 3.29 times, where the most pronounced relative increases were seen for ATC groups A (6.31 times), B (2.29 times), J (4.50 times), M (2.25 times) and N (3.18 times). For ATC group D, the increase was from 0 to 10 , and for group G from 0 to 18 . There was a trend for higher increase in medication in individuals with traumatic vs non-traumatic SCL. Some details not shown in Table 3: In the overall population, the number of group B medicines was only seven before the SCL: three acetylsalicylic acid, one iron, two vitamin B12 and one folic acid. After the SCL sixteen group B medicines were used: one acetylsalicylic acid, ten iron, two vitamin $\mathrm{B} 12$, one folic acid, one vitamin $\mathrm{K}$ antagonist and one low molecular heparin. Group D medications were not used before the SCL. After the SCL all ten group D medications were for topical application: three were antifungal, two were against eczema, three were against seborrheic dermatitis, one was an ointment for treatment of fragile scar tissue and one was minoxidil for cosmetic treatment of baldness. No group G medications were used before the SCL, whereas after the SCL tolterodine was used in seven patients, sildenafil in seven, estradiol in two and tamsulosin in two. For group J, one patient used dicloxacillin, and one used nitrofurantoine before the SCL, whereas after the SCL mecillinam, trimethoprim, ciprofloxacin and fluconazole were used by five, one, two and one patients, respectively.

The influence of gender on the medicine use before and after SCL can be seen in Table 4. Men showed a trend for higher increase in total medication consumption than women. As shown men were significantly younger than women.

The influence of the level of the neurological lesion, that is paraplegia vs tetraplegia is illustrated in Table 5. The overall relative increase in medication usage was practically the same for the paraplegic and tetraplegic patients, although for some ATC groups, trends were observed.

The associations between the AIS grade and the increase in medicine consumption are seen in Table 6. Patients with AIS D (the less severe SCLs) had a relatively higher use of medicines before the injury (123 drugs for 35 persons) compared with patients with AIS A, B or C (the more severe SCLs) (65 drugs for 33 persons). Generally, patients with AIS A, B or C compared with patients with AIS D had a higher increase in total medicine consumption after the SCL (4.74 vs 2.53 times; $P<0.05$ ), especially for ATC category A (18.00 vs 3.39 times; $P<0.001$ ).

The influence of age on increase in medicine consumption after an SCL is illustrated in Table 7. There was a trend toward a relatively lower increase in medicine consumption with age: for the age intervals $0-45,46-60$ and $60+$, the increases after an SCL were $9.40,4.83$ and 2.21 , respectively.

\section{DISCUSSION}

Medications may offer a great help and at the same time cause adverse events. There are innumerous interactions between various medicines, between medicine and food, and between medicine and diseases. Furthermore, medications are an economic burden for the patients and for the society. Polypharmacy is a problem especially in chronically ill and in the elderly. One part of the dramatic transition 
Table 2 Age, gender, level (tetraplegia, paraplegia) and severity (by the American Spinal Injury Association Impairment Scale (AIS)) of lesion by cause of the spinal cord lesion (traumatic, non-traumatic) of the 68 patients with data on medication before and after the spinal cord lesion

\begin{tabular}{|c|c|c|c|}
\hline & All & Non-traumatic & Traumatic \\
\hline & $68(100 \%)$ & $40(59 \%)$ & $28(41 \%)$ \\
\hline Mean age & 57.3 (s.d.:16.8; median: 60; range 13-90) & 60.2 (s.d.:14.9; median: 62, range: 13-90) & 53.2 (s.d.:18.3; median: 53, range: 25-89) \\
\hline Women & $26(38 \%)$ & $21(53 \%)$ & $5(18 \%)$ \\
\hline Men & $42(62 \%)$ & $19(47 \%)$ & $23(82 \%)$ \\
\hline Paraplegia & $37(54 \%)$ & $27(67 \%)$ & $10(36 \%)$ \\
\hline Tetraplegia & $31(46 \%)$ & $13(33 \%)$ & $18(64 \%)$ \\
\hline AIS $A, B, C$ & $33(49 \%)$ & $16(40 \%)$ & $17(61 \%)$ \\
\hline AIS D & $35(51 \%)$ & $24(60 \%)$ & $11(39 \%)$ \\
\hline
\end{tabular}

The difference in age between the two populations was tested by a two-tailed $t$-test with $P=0.093$.

Table 3 All patients and patients divided according to non-traumatic or traumatic cause of their spinal cord lesion (SCL)

\begin{tabular}{|c|c|c|c|c|c|c|}
\hline & \multicolumn{2}{|l|}{$A / /(\mathrm{N}=68)$} & \multicolumn{2}{|l|}{ Non traumatic $(\mathrm{N}=40)$} & \multicolumn{2}{|l|}{ Traumatic $(\mathrm{N}=28)$} \\
\hline & $\begin{array}{c}\text { Number of medications after } \\
\text { divided by number of } \\
\text { medications before SCL }\end{array}$ & $\begin{array}{c}\mathrm{P}- \\
\text { value }^{\mathrm{a}}\end{array}$ & $\begin{array}{c}\text { Number of medications after } \\
\text { divided by number of } \\
\text { medications before SCL }\end{array}$ & $\begin{array}{c}\mathrm{P}- \\
\text { value }^{\mathrm{a}}\end{array}$ & $\begin{array}{c}\text { Number of medications after } \\
\text { divided by number of } \\
\text { medications before } S C L\end{array}$ & $\begin{array}{c}\text { P- } \\
\text { value }^{\mathrm{a}}\end{array}$ \\
\hline A. Alimentary tract and metabolism & $221 / 35=6.31$ & 0.000 & $127 / 23=5.52$ & 0.000 & $94 / 12=7.83$ & 0.000 \\
\hline B. Blood and blood forming organs & $16 / 7=2.29$ & 0.028 & $10 / 4=2.50$ & 0.028 & $6 / 3=2.00$ & 0.310 \\
\hline C. Cardiovascular system & $62 / 40=1.55$ & 0.005 & $48 / 31=1.55$ & 0.012 & $14 / 9=1.56$ & 0.237 \\
\hline D. Dermatologicals & $10 / 0=-$ & 0.008 & $6 / 0=-$ & 0.043 & $4 / 0=-$ & 0.068 \\
\hline G. Genito-urinary system and sex hormones & $18 / 0=-$ & 0.000 & $10 / 0=-$ & 0.005 & $8 / 0=-$ & 0.012 \\
\hline $\begin{array}{l}\text { H. Systemic hormonal preparations, excluding } \\
\text { sex hormones and insulins }\end{array}$ & $3 / 2=1.50$ & 0.593 & $2 / 1=2.00$ & 0.593 & $1 / 1=1.00$ & 1.000 \\
\hline J. Antiinfectives for systemic use & $9 / 2=4.50$ & 0.038 & $7 / 2=3.50$ & 0.091 & $2 / 0=-$ & 0.180 \\
\hline $\begin{array}{l}\text { L. Antineoplastic and immunomodulating } \\
\text { agents }\end{array}$ & $2 / 2=1.00$ & 1.000 & $1 / 1=1.00$ & 1.000 & $1 / 1=1.00$ & 1.000 \\
\hline M. Musculo-skeletal system & $45 / 20=2.25$ & 0.002 & $27 / 14=1.93$ & 0.066 & $18 / 6=3.00$ & 0.006 \\
\hline N. Nervous system & $216 / 68=3.18$ & 0.000 & $133 / 53=2.51$ & 0.000 & $83 / 15=5.53$ & 0.000 \\
\hline $\begin{array}{l}\text { P. Antiparasitic products, insecticides and } \\
\text { repellents }\end{array}$ & $2 / 2=1.00$ & 1.000 & $2 / 1=2.00$ & 0.593 & $0 / 1=0.00$ & 0.423 \\
\hline R. Respiratory system & $13 / 9=1.44$ & 0.359 & $5 / 6=0.83$ & 0.753 & $8 / 3=2.67$ & 0.068 \\
\hline S. Sensory organs & $1 / 1=1.00$ & 1.000 & $1 / 1=1.00$ & 1.000 & $0 / 0=-$ & 1.000 \\
\hline V. Various & $1 / 0=-$ & 0.317 & $1 / 0=-$ & 0.317 & $0 / 0=-$ & 1.000 \\
\hline Total number of drugs & $619 / 188=3.29$ & 0.000 & $380 / 137=2.77$ & 0.000 & $239 / 51=4.69$ & 0.000 \\
\hline
\end{tabular}

The number of medications in each category is accumulated for all the patients.

aThe difference in medication before and after SCL has been compared with the two paired sample Wilcoxon-signed rank test using the two-sided $P$-value for statistical significance.

of an SCL is often the concomitant need for several kinds of medicine from 1 day to another. In the present work, we have mapped some details of this sudden change distinguishing between traumatic vs non-traumatic SCL, genders, paraplegia vs tetraplegia, AIS A, B or C vs $\mathrm{D}$ and various age groups. To our knowledge, the present study is the first to elucidate the general issue related to medication when having a new SCL. The study is meant as a contribution to a mapping out of changes in medication thus facilitating more specific studies on medicine consumption in relation to SCL.

When considering all medications and all patients, the overall increase in total medicine consumption after an SCL was 3.29 times (Table 3). Practically, all ATC groups of medications showed an increase. However, the most conspicuous was the 6.31 times increase seen for ATC group A (alimentary tract and metabolism) reflecting the need of laxatives after the SCL. ${ }^{7}$ Also, ATC group G (genitourinary system and sex hormones) was significantly increased reflecting the SCL impact on genito-urinary system. ${ }^{13,14}$ The ATC group $\mathrm{N}$ (nervous system) also showed a highly significant increase after an SCL. This probably reflects both more pain after the SCL and the frequent advent of spasticity. ${ }^{15}$ The same was probably the case for the increase in ATC group M (musculoskeletal system) medications. ${ }^{16}$

The significant increase in ATC group C (cardiovascular system) may reflect the dysfunctional autonomic and cardiovascular regulation after the SCL. ${ }^{17}$ The increase in ATC group C is seen more or less in all age groups, although most pronounced in the youngest. In addition, persons with SCL are subjected to extreme physical inactivity that may have an influence on their lipid profile and lipoprotein concentration leading to more cardiovascular disease, maybe as a part of premature aging. ${ }^{18}$

ATC group D (dermatologicals) showed a significant increase most pronounced in AIS A, B and C, indicating that it is associated with the more severe SCL. The increase in use of dermatological drugs 
Table 4 The influence of gender on medication before and after the spinal cord lesion (SCL)

\begin{tabular}{|c|c|c|c|c|}
\hline \multirow[t]{3}{*}{ Gender } & \multicolumn{2}{|l|}{ Women $(\mathrm{N}=26)$} & \multicolumn{2}{|l|}{ Men $(\mathrm{N}=42)$} \\
\hline & \multicolumn{2}{|c|}{$\begin{array}{c}\text { Mean age: } 64.7 \text { years }^{\mathrm{a}} \\
\text { (s.d.:13.1; median: 62; range: 34-90) }\end{array}$} & \multicolumn{2}{|c|}{$\begin{array}{c}\text { Mean age: } 52.9 \text { years }^{\text {a }} \\
\text { (s.d.:17.3; median:53; range:13-84) }\end{array}$} \\
\hline & $\begin{array}{l}\text { Number of medications after divided } \\
\text { by number of medications before SCL }\end{array}$ & $\begin{array}{l}\text { P- } \\
\text { value }\end{array}$ & $\begin{array}{l}\text { Number of medications after divided } \\
\text { by number of medications before SCL }\end{array}$ & $\begin{array}{c}\mathrm{P}- \\
\text { value }^{\mathrm{b}}\end{array}$ \\
\hline A. Alimentary tract and metabolism & $88 / 20=4.40$ & 0.000 & $133 / 15=8.87$ & 0.000 \\
\hline B. Blood and blood forming organs & $5 / 2=2.50$ & 0.109 & $11 / 5=2.20$ & 0.093 \\
\hline C. Cardiovascular system & $26 / 14=1.85$ & 0.045 & $36 / 26=1.38$ & 0.047 \\
\hline D. Dermatologicals & $3 / 0=-$ & 0.109 & $7 / 0=-$ & 0.028 \\
\hline G. Genito-urinary system and sex hormones & $4 / 0=-$ & 0.068 & $14 / 0=-$ & 0.001 \\
\hline H. Systemic hormonal preparations, excluding sex hormones and insulins & $1 / 1=1.00$ & 1.000 & $2 / 1=2.00$ & 0.317 \\
\hline J. Antiinfectives for systemic use & $6 / 1=6.00$ & 0.043 & $3 / 1=3.00$ & 0.361 \\
\hline L. Antineoplastic and immunomodulating agents & $1 / 1=1.00$ & 1.000 & $1 / 1=1.00$ & 1.000 \\
\hline M. Musculo-skeletal system & $16 / 8=2.00$ & 0.098 & $29 / 12=2.42$ & 0.010 \\
\hline N. Nervous system & $103 / 41=2.51$ & 0.000 & $113 / 27=4.19$ & 0.000 \\
\hline P. Antiparasitic products, insecticides and repellents & $1 / 0=-$ & 0.317 & $1 / 2=0.50$ & 0.593 \\
\hline R. Respiratory system & $5 / 5=1.00$ & 1.000 & $8 / 4=2.00$ & 0.178 \\
\hline S. Sensory organs & $0 / 1=0.00$ & 0.317 & $1 / 0=-$ & 0.317 \\
\hline V. Various & $1 / 0=-$ & 0.317 & $0 / 0=-$ & 1.000 \\
\hline Total number of drugs & $260 / 94=2.77$ & 0.000 & $359 / 94=3.82$ & 0.000 \\
\hline
\end{tabular}

The number of medicines in each category is accumulated for all the patients.

aThe difference in age between women and men was tested by a two-tailed $t$-test with $P<0.002$.

bThe difference in medication before and after SCL has been compared with the two paired sample Wilcoxon-signed rank test using the two-sided $P$-value for statistical significance.

Table 5 Change in consumption of medications according to level of the spinal cord lesion (SCL)

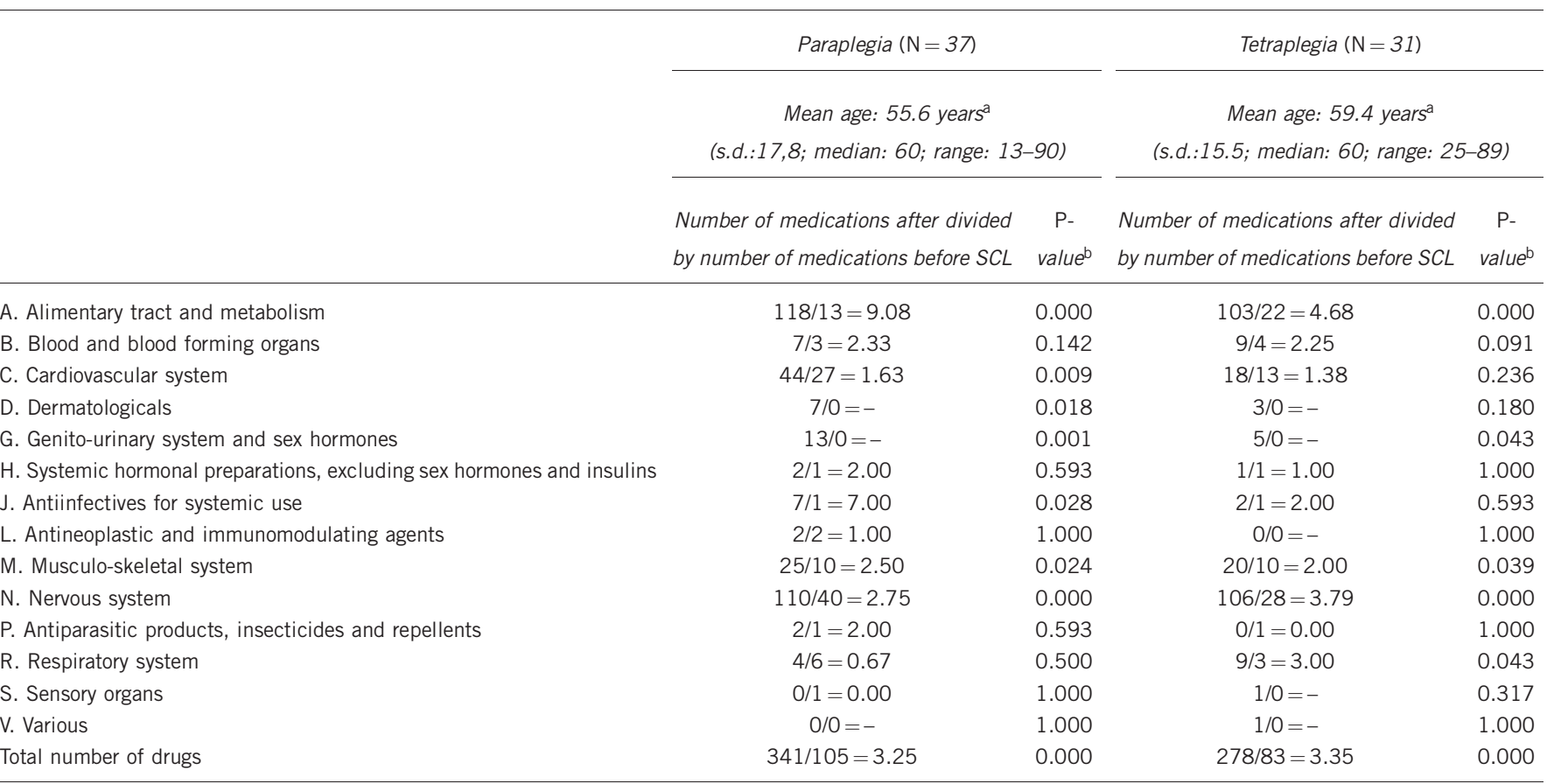

The number of medications in each category is accumulated for all the patients.

aThe difference in age between the two populations was tested by a two-tailed $t$-test with $P=0.360$.
bThe difference in medication before and after SCL has been compared with the two paired sample Wilcoxon-signed rank test using the two-sided $P$-value for statistical significance.

was not because of pressure sores, but primarily reflected fungal infections, eczema and seborrheic dermatitis.

The overall increase in ATC group B (blood and blood forming organs) primarily reflected a 10 -fold increase in the consumption of iron preparations rather than antithrombotic treatments, which are mainly used the first 3 months after an SCL.

The increased use of ATC group J (antiinfectives for systemic use) is most constantly seen in women, and in paraplegic patients. The 
Table 6 Change in consumption of medications before and after spinal cord lesion (SCL) according to severity

\begin{tabular}{|c|c|c|c|c|}
\hline & \multicolumn{2}{|l|}{ AIS $A, B$ or $C(N=33)$} & \multicolumn{2}{|l|}{ AIS $D(\mathrm{~N}=35)$} \\
\hline & \multicolumn{2}{|c|}{$\begin{array}{l}\text { Mean age: } 55.7 \text { years }^{\mathrm{a}} \\
\text { (s.d.:20.1; median: 62; range: 29-83) }\end{array}$} & \multicolumn{2}{|c|}{$\begin{array}{l}\text { Mean age: } 58.9 \text { years }^{\mathrm{a}} \\
\text { (s.d.:13.0; median: 59; range: 13-90) }\end{array}$} \\
\hline & $\begin{array}{l}\text { Number of medications after divided } \\
\text { by number of medications before } S C L\end{array}$ & $\begin{array}{c}\mathrm{P}- \\
\text { value }^{\mathrm{b}}\end{array}$ & $\begin{array}{l}\text { Number of medications after divided } \\
\text { by number of medications before } S C L\end{array}$ & $\begin{array}{c}\text { P- } \\
\text { value }^{\mathrm{b}}\end{array}$ \\
\hline A. Alimentary tract and metabolism & $126 / 7=18.00$ & 0.000 & $95 / 28=3.39$ & 0.000 \\
\hline B. Blood and blood forming organs & $7 / 3=2.33$ & 0.208 & $9 / 4=2.25$ & 0.043 \\
\hline C. Cardiovascular system & $27 / 18=1.50$ & 0.059 & $35 / 22=1.59$ & 0.038 \\
\hline D. Dermatologicals & $7 / 0=-$ & 0.028 & $3 / 0=-$ & 0.109 \\
\hline G. Genito-urinary system and sex hormones & $10 / 0=-$ & 0.003 & $8 / 0=-$ & 0.012 \\
\hline H. Systemic hormonal preparations, excluding sex hormones and insulins & $2 / 1=2.00$ & 0.593 & $1 / 1=1.00$ & 1.000 \\
\hline J. Antiinfectives for systemic use & $6 / 2=3.00$ & 0.142 & $3 / 0=-$ & 0.109 \\
\hline L. Antineoplastic and immunomodulating agents & $0 / 0=-$ & 1.000 & $2 / 2=1.00$ & 1.000 \\
\hline M. Musculo-skeletal system & $26 / 10=2.60$ & 0.013 & $19 / 10=1.90$ & 0.078 \\
\hline N. Nervous system & $91 / 23=3.96$ & 0.000 & $125 / 45=2.78$ & 0.000 \\
\hline P Antiparasitic products, insecticides and repellents & $0 / 0=-$ & 1.000 & $2 / 2=1.00$ & 1.000 \\
\hline R. Respiratory system & $5 / 1=5.00$ & 0.178 & $8 / 8=1.00$ & 1.000 \\
\hline S. Sensory organs & $1 / 0=-$ & 0.317 & $0 / 1=0.00$ & 0.317 \\
\hline V. Various & $0 / 0=-$ & 1.000 & $1 / 0=-$ & 0.317 \\
\hline Total number of drugs & $308 / 65=4.74$ & 0.000 & $311 / 123=2.53$ & 0.000 \\
\hline
\end{tabular}

Patients are divided according to the American Spinal Injury Association Impairment Scale (AIS) into grade A, B or C vs AIS D. The number of medications in each category is accumulated for all the patients.

${ }^{a}$ The difference in age between the two populations was tested by a two-tailed $t$-test with $P=0.446$.

bThe difference in medication before and after the SCL has been compared with the two paired sample Wilcoxon-signed rank test using the two-sided $P$-value for statistical significance.

Table 7 Medication before and after spinal cord lesion (SCL) according to age in intervals of $0-45,46-60$ and $60+$ years at time of SCL

\begin{tabular}{|c|c|c|c|c|c|c|}
\hline & \multicolumn{2}{|l|}{$0-45$ years $(N=16)$} & \multicolumn{2}{|l|}{$46-60$ years $(\mathrm{N}=19)$} & \multicolumn{2}{|l|}{$60+\operatorname{years}(\mathrm{N}=33)$} \\
\hline & \multicolumn{2}{|c|}{$\begin{array}{c}\text { Mean age: } 33.8 \text { years } \\
\text { (s.d.:8.4; median: 34; range: } 13-45 \text { ) }\end{array}$} & \multicolumn{2}{|c|}{$\begin{array}{c}\text { Mean age: } 53.7 \text { years } \\
\text { (s.d.:4.8; median: } 54 \text {; range: 47-60) }\end{array}$} & \multicolumn{2}{|c|}{$\begin{array}{c}\text { Mean age: } 70.8 \text { years } \\
\text { (s.d.:8.5; median: 69; range: } 61-90)\end{array}$} \\
\hline & $\begin{array}{c}\text { Number of medications after } \\
\text { divided by number of medications } \\
\text { before } S C L\end{array}$ & $\begin{array}{c}\mathrm{P}- \\
\text { value }\end{array}$ & $\begin{array}{c}\text { Number of medications after } \\
\text { divided by number of medications } \\
\text { before } S C L\end{array}$ & $\begin{array}{c}\mathrm{P}- \\
\text { value }\end{array}$ & $\begin{array}{c}\text { Number of medications after } \\
\text { divided by number of medications } \\
\text { before } S C L\end{array}$ & $\begin{array}{c}\text { P- } \\
\text { value }\end{array}$ \\
\hline A. Alimentary tract and metabolism & $52 / 2=26.00$ & 0.001 & $63 / 5=12.60$ & 0.000 & $106 / 28=3.79$ & 0.000 \\
\hline B. Blood and blood forming organs & $4 / 0=-$ & 0.068 & $3 / 1=3.00$ & 0.180 & $9 / 6=1.50$ & 0.310 \\
\hline C. Cardiovascular system & $7 / 1=7.00$ & 0.109 & $13 / 10=1.30$ & 0.109 & $42 / 29=1.45$ & 0.047 \\
\hline D. Dermatologicals & $4 / 0=-$ & 0.109 & $2 / 0=-$ & 0.180 & $4 / 0=-$ & 0.068 \\
\hline $\begin{array}{l}\text { G. Genito-urinary system and sex } \\
\text { hormones }\end{array}$ & $8 / 0=-$ & 0.012 & $5 / 0=-$ & 0.043 & $5 / 0=-$ & 0.043 \\
\hline M. Musculo-skeletal system & $11 / 2=5.50$ & 0.022 & $15 / 5=3.00$ & 0.041 & $19 / 13=1.46$ & 0.251 \\
\hline N. Nervous system & $49 / 6=8.17$ & 0.001 & $67 / 13=5.15$ & 0.000 & $100 / 49=2.04$ & 0.001 \\
\hline $\begin{array}{l}\text { P. Antiparasitic products, insecticides } \\
\text { and repellents }\end{array}$ & $0 / 0=-$ & 1.000 & $1 / 0=-$ & 0.317 & $1 / 2=0.50$ & 0.593 \\
\hline R. Respiratory system & $3 / 2=1.50$ & 0.593 & $2 / 2=1.00$ & 1.000 & $8 / 5=1.60$ & 0.273 \\
\hline S. Sensory organs & $1 / 0=-$ & 0.317 & $0 / 0=-$ & 1.000 & $0 / 1=0.00$ & 0.317 \\
\hline V. Various & $0 / 0=-$ & 1.000 & $0 / 0=-$ & 1.000 & $1 / 0=-$ & 0.317 \\
\hline Total number of drugs & $141 / 15=9.40$ & 0.000 & $174 / 36=4.83$ & 0.000 & $303 / 137=2.21$ & 0.000 \\
\hline
\end{tabular}

The number of medications in each category is accumulated for all the patients.

aThe difference in medication before and after the SCL has been compared with the two paired sample Wilcoxon-signed rank test using the two-sided $P$-value for statistical significance. 
increased use mainly reflects that SCL predisposes to urinary tract infections. ${ }^{19}$

There may be interrelationships between observations reported in the different tables. Table 2 indicates that traumatic patients are 7 years younger than non-traumatic patients. Of the traumatic patients, $82 \%$ were men, $64 \%$ were tetraplegic and $61 \%$ have more severe SCL (AIS A, B or C). For the non-traumatic patients, the relationship is almost the opposite. Generally, these relationships with traumatic patients as a starting point are reflected in the tables with a general tendency to higher increase in medicine consumption for traumatic patients, for men, for tetraplegics, for more severe SCL according to AIS and for younger persons. However, when comparing the increases in medication between groups, statistically significant differences were only seen between AIS A, B, $\mathrm{C}$ and AIS D.

There are limitations related to this study. As an SCL affects nearly all body functions negatively, practically all ATC groups may be needed. Therefore, we have chosen to use the 14 main groups of the ATC classification. After all we find it the most comprehensive way to map out the use of medications, although it has shortcomings. For example, ATC group A comprises both metabolic medications like antidiabetics and strictly gastrointestinal drugs like antacids, in ATC group B you find both vitamin B12 and antithrombotics, in ATC group $\mathrm{C}$ there are diuretics and medications against hemorrhoids and so on.

Another limitation is that for 4 persons out of 72 it was not feasible to have information on their medicine consumption before the SCL. However, still 68 persons with SCL could be included (94\%) which can be considered as satisfactory.

The registration of medicines used before the SCL is based on retrieval of information from medical records, electronic registrations of medicine and sometimes confirmation from the patients. Theoretically, some medications used before the SCL could have missed registration. However, the main outcome of the calculations is the relation between medications taken before and after the SCL followed by comparisons between the groups, for example between men and women. Still, this aspect could have some impact on the results especially when comparing younger and older persons. The elderly may have a less good memory at the same time as they may be in need of remembering more medications.

A further limitation is the inclusion of on-demand medications in the calculations with the same weight as the regular medications, as the SCL patients are in special need of on-demand medications as they may suffer from constipation and pain intermittently more often than other patient groups.

However, it would be valuable with further studies mapping the impact of SCL on medicine consumption in other clinics and countries. But even differences in prescriptions when comparing clinics could add constructive information on ways how to manage the challenges in optimizing the treatment of SCL patients. It would be of interest to search for approaches alternative to medicine treatment to minimize the potential adverse events, interactions and economical load on patients and society.

\section{CONCLUSION}

SCL has a considerable impact on the use of medicine. The most pronounced increases in consumption of medicine were for ATC groups A, G, N followed by M, C, D, B and J all reflecting the organ systems clinically most affected in individuals with SCL. The highest increases in medicine consumption were detected in the more severe SCL (AIS A, B, C) patients. Paraplegic and tetraplegic patients showed nearly the same increase in total medicine consumption.

\section{DATA ARCHIVING}

There were no data to deposit.

\section{CONFLICT OF INTEREST}

The authors declare no conflict of interest.

1 Frankel HL, Coll JR, Charlifue SW, Whiteneck GG, Gardner BP, Jamous MA et al. Long-term survival in spinal cord injury: a fifty year investigation. Spinal Cord 1998; 36: 266-274.

2 Hartkopp A, Brønnum-Hansen H, Seidenschnur A-M, Biering-Sørensen F. Survival and cause of death after traumatic spinal cord injury. A long-term epidemiological survey from Denmark. Spinal Cord 1997; 35: 78-85.

3 Lidal IB, Snekkevik H, Aamodt G, Hjeltnes N, Biering-Sørensen F, Stanghelle JK. Mortality after spinal cord injury in Norway. J Rehabil Med 2007; 39: 145-151.

4 DeVivo MJ. Epidemiology of traumatic spinal cord injury: trends and future implications. Spinal Cord 2012; 50: 365-372.

5 Stöhrer M, Blok B, Castro-Diaz D, Chartier-Kastler E, Del Popolo G, Kramer G et al. EAU guidelines on neurogenic lower urinary tract dysfunction. Eur Urol 2009; 56: 81-88.

6 Consortium for Spinal Cord Medicine. Bladder management for adults with spinal cord injury: a clinical practice guideline for health-care providers. J Spinal Cord Med 2006; 29: 527-573.

7 Awad RA. Neurogenic bowel dysfunction in patients with spinal cord injury, myelomeningocele, multiple sclerosis and Parkinson's disease. World J Gastroenterol 2011; 17: 5035-5048.

8 Krassioukov A, Eng JJ, Claxton G, Sakakibara BM, Shum S. Neurogenic bowel management after spinal cord injury: a systematic review of the evidence. Spinal Cord 2010; 48: 718-733

9 Krogh K, Nielsen J, Djurhuus JC, Mosdal C, Sabroe S, Laurberg S. Colorectal function in patients with spinal cord lesions. Dis Colon Rectum 1997; 40: 1233-1239.

10 Atkins D, Noonan VK, Santos A, Lewis R, Fehlings M, Burns A et al. Secondary complications in $\mathrm{SCl}$ across the continuum: Using operations research to predict the impact and optimize management strategies. Top Spinal Cord Inj Rehabil 2012; 18: 57-66.

11 Hitzig SL, Tonack M, Campbell KA, McGillivray CF, Boschen KA, Richards K et al. Secondary health complications in an aging Canadian spinal cord injury sample. $A m \mathrm{~J}$ Phys Med Rehabil 2008; 87: 545-555.

12 Kirshblum SC, Burns SP, Biering-Sorensen F, Donovan W, Graves DE, Jha A et al. International standards for neurological classification of spinal cord injury (Revised 2011). J Spinal Cord Med 2011; 34: 535-546.

13 Barbonetti A, Cavallo F, Felzani G, Francavilla S, Francavilla F. Erectile dysfunction is the main determinant of psychological distress in men with spinal cord injury. J Sex Med 2012; 9: 830-836.

14 Mahfouz W, Corcos J. Management of detrusor external sphincter dyssynergia in neurogenic bladder. Eur J Phys Rehabil Med 2011; 47: 639-650.

15 Finnerup NB, Baastrup C. Spinal cord injury pain: mechanisms and management. Curr Pain Headache Rep 2012; 16: 207-216.

16 Rekand T, Hagen EM, Grønning M. Chronic pain following spinal cord injury. Tidsskr Nor Laegeforen 2012; 132: 974-979.

17 Krassioukov A, Claydon VE. The clinical problems in cardiovascular control following spinal cord injury: an overview. Prog Brain Res 2006; 152: 223-229.

18 Hitzig SL, Eng JJ, Miller WC, Sakakibara BM; SCIRE Research Team. An evidencebased review of aging of the body systems following spinal cord injury. Spinal Cord 2011; 49: 684-701.

19 Biering-Sørensen F. Urinary tract infection in individuals with spinal cord lesion. Curr Opin Urol 2002; 12: 45-49. 